\title{
PROBABILISTIC ESTIMATION OF DEBRIS-FLOW OCCURRENCE AFTER EXTREME RAINFALLS
}

\author{
J.C. $\mathrm{CHEN}^{1}$, J.G. JIANG ${ }^{1}$ \& W.S. HUANG ${ }^{2}$ \\ ${ }^{1}$ Department of Environmental and Hazards-Resistant Design, Huafan University, Taiwan. \\ ${ }^{2}$ Ecological Soil and Water Conservation Research Center, National Cheng Kung University, Taiwan.
}

\begin{abstract}
This article studied the debris-flow occurrence and the corresponding extreme rainfall events, as well as a severe earthquake, the Chi-Chi earthquake (CCE), in Chenyulan watershed, Taiwan. By examining the associations between the rainfall index (RI), defined as the product of the maximum 24-h rainfall and maximum hourly rainfall of a rainfall event, the return period $(\mathrm{T})$, and the probability $(P)$ of debris flow after an event, an empirical model of the $P-T$ relationship was developed and this model was applied to evaluate an extreme rainfall event, Typhoon Morakot. Results of this study showed that debris flows could be triggered at lower RI values, corresponding with lower $T$ values, for rainfall events after extreme rainfalls or after the CCE. The extreme events mostly had $T$ values exceeding eight years. The $T$ value for the critical RI affected by the CCE was approximately one year, much smaller than that affected by extreme events. $P$ rose significantly after an extreme rainfall event or the CCE at the same $T$. The $P$ value affected by CCE was markedly higher than that affected by extreme rainfalls. In addition, field data of debris-flow occurrence and rainfall between 2012 and 2014 were collected to assess the proposed model. The model was successfully applied to evaluate the probability of debris-flow occurrence after extreme rainfalls.

Keywords: Chenyulan watershed, probability of debris-flow occurrence, rainfall index, return period
\end{abstract}

\section{INTRODUCTION}

Extreme events such as extreme rainfall and major earthquakes can cause landslides and debris flows in mountainous watersheds, which generally deposit large amounts of loose debris in gullies and on slopes [1,2] and increase the volume of loose debris within a watershed. The supply of loose debris has an important role in the occurrence of future debris flows and may change the critical rainfall threshold for the initiation of debris flows during subsequent rainfall events [3]. In other words, the critical rainfall threshold for debris-flow initiation may differ before and after an extreme rainfall event or major earthquake. Therefore, understanding the variations in rainfall characteristics after extreme events and their influence on debris-flow initiation is important for the implementation of debris-flow warnings and hazard mitigation.

Previous investigators have studied debris flows following major earthquakes, such as the effects of the Chi-Chi earthquake (CCE) on the characteristics of debris flows in Taiwan $[4,5]$, the variation in rainfall conditions required to trigger debris flows and the affected period after the CCE [6], as well as the impact of the Wenchuan earthquake in China on subsequent long-term debris-flow activity [7]. Chen et al. [2] studied recent changes in the number of rainfall events related to debris-flow occurrence. They found that the number of extreme rainfall events in the Chenyulan watershed showed an increasing trend. Chen et al. [8] analysed the characteristics of rainfall related to debris-flow occurrence in the Chenyulan watershed to investigate the variation in the rainfall conditions related to debris-flow occurrences and the empirical relationship between rainfall characteristics and the corresponding number of debris flows. Extreme rainfall events and the CCE were shown to affect the critical condition for the occurrence of debris flows in the Chenyulan watershed. The CCE 
significantly lowered the critical rainfall threshold for debris-flow occurrence in the subsequent five years [8]. The period of critical rainfall index (RI) for debris-flow occurrence could be lowered to approximately three years after extreme rainfalls [9]. The return period $(T)$, also referred to as the recurrence interval, is an important concept that reflects the longterm hydrological characteristics of an area, which is useful for hydrological or hydraulic design. However, there is a lack of studies quantifying the rainfall threshold of debris-flow occurrence associated with return period. Therefore, this study determines the relationship between the $T$ of rainfall characteristics associated with the probability of debris-flow occurrence $(P)$ and applies the relationship between $P$ and $T$ to evaluate the probability of debrisflow initiation, especially after rainfall and other extreme events. The Chenyulan watershed in central Taiwan was selected as a study area, because it has experienced both earthquakes (i.e., the CCE) and extreme rainfall events.

\section{STUDY AREA}

The watershed of the Chenyulan River, located in Nantou County, central Taiwan (Fig. 1), has an area of $449 \mathrm{~km}^{2}$, main stream length of $42 \mathrm{~km}$, average stream-bed gradient of $4^{\circ}$ and elevation range of $310-3,952 \mathrm{~m}$. The annual regional rainfall in the watershed is between

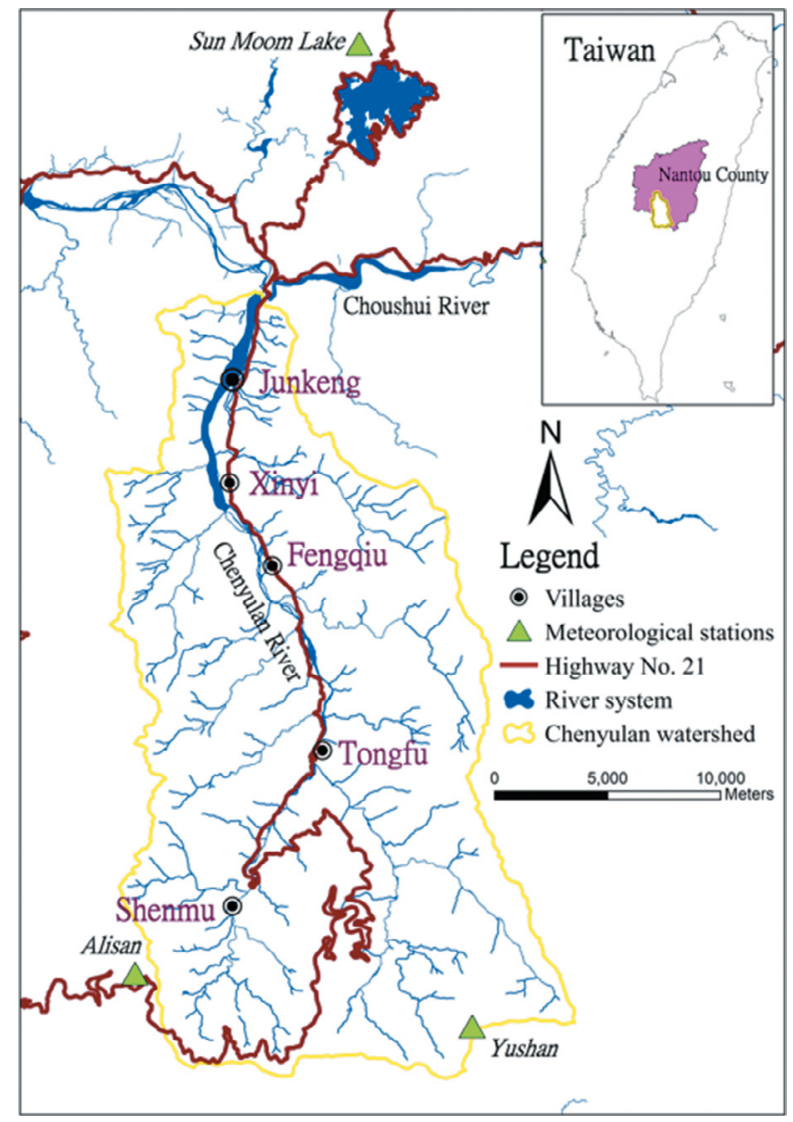

Figure 1: Location of the Chenyulan watershed in central Taiwan. 
2,000 and 5,000 $\mathrm{mm}$, with an average of approximately 3,500 $\mathrm{mm}$. The CCE occurred on 21 September 1999 with a magnitude of 7.6 on the moment magnitude scale and 7.3 on the Richter scale, and was the largest earthquake in Taiwan in 100 years [10]. It caused numerous landslides in the Chenyulan watershed. Owing to steep topography, loose soils, young (three million years) and weak geological formations due to ongoing orogenesis, heavy rainfall and active earthquakes, many debris flows were triggered by more than 30 rainfall events, including five extreme rainfall events, in the past five decades in the watershed [8].

\subsection{RI and extreme rainfall events}

The occurrence of debris flow depends not only on the accumulated rainfall but also on the rainfall intensity. The RI, defined as the product of the maximum 24-h rainfall $\left(R_{\mathrm{d}}\right)$ and the maximum hourly rainfall $\left(I_{\mathrm{m}}\right)$, i.e., $\mathrm{RI}=R_{\mathrm{d}} I_{\mathrm{m}}$, of a rainfall event, was used to indicate either high accumulated rainfall or high rainfall intensity that could trigger debris flows. The RI was used by Chen et al. [8] to study the characteristics of rainfall triggering of debris flows in the Chenyulan watershed, in which $R_{\mathrm{d}}$ and $I_{\mathrm{m}}$ are determined from regional hourly rainfall data from three stations (Sun Moon Lake, Yushan, and Alisan stations, as shown in Figure 1) via the reciprocal-distance-squared method. Table 1 lists the debris flow events and related rainfall characteristics for five extreme rainfalls. The five extreme rainfall events included Typhoon Herb (TH) in 1996, Typhoon Toraji (TT) in 2001, Typhoon Mindulle (TMi) in 2004, a heavy rainstorm (HR) in 2006 and Typhoon Morakot (TM) in 2009. These events had the highest critical RI values of all rainfall events from 1963 to 2016 , with RI $>365 \mathrm{~cm}^{2} / \mathrm{h}$, as shown in Fig. 2. Each of these five events caused ten or more debris flows in the watershed.

\subsection{Variations in the RI}

Extreme rainfall events and the CCE have been shown to affect the critical conditions required for the occurrence of debris flows, and the critical RI values for occurrence of debris flows have been classified into four categories [11], as shown in Fig. 2: the periods before $\mathrm{TH}$, between TH and CCE, between CCE and TMi and between TMi and TM. These periods had critical RI values of approximately $165,60,2$ and $100 \mathrm{~cm}^{2} / \mathrm{h}$, respectively. These trends showed that TH caused numerous landslides and debris flows in the watershed, which reduced the critical rainfall threshold for debris flows in subsequent years and the CCE significantly

Table 1: Debris-flow events and related rainfall characteristics for five extreme rainfalls in the Chenyulan watershed (Chen et al. [8]).

\begin{tabular}{llccrc}
\hline Extreme rainfall event & Date & $N$ & $I_{\mathrm{m}}(\mathrm{mm} / \mathrm{h})$ & $R_{\mathrm{d}}(\mathrm{mm})$ & $\mathrm{RI}\left(\mathrm{cm}^{2} / \mathrm{h}\right)$ \\
\hline Typhoon Herb & 31 July-1 August 1996 & $>35$ & 71.6 & $1,181.6$ & 846.0 \\
Typhoon Toraji & 29-30 July 2001 & $>75$ & 78.5 & 587.6 & 461.3 \\
Typhoon Mindulle & 02-03 July 2004 & $>15$ & 54.0 & 681.4 & 368.0 \\
Heavy rainstorm & 08-11 June 2006 & $>10$ & 77.5 & 682.8 & 529.2 \\
Typhoon Morakot & 06-11 August 2009 & $>40$ & 85.5 & $1,192.6$ & $1,019.7$ \\
\hline
\end{tabular}

Note: $N=$ total number of individual debris flows triggered by each rainfall event in the Chenyulan watershed; $I_{\mathrm{m}}=$ maximum hourly rainfall in each rainfall event; $R_{\mathrm{d}}=$ maximum 24 -h rainfall amount in each rainfall event; $\mathrm{RI}=$ rainfall index, $\mathrm{RI}=R_{\mathrm{d}} I_{\mathrm{m}}$. 


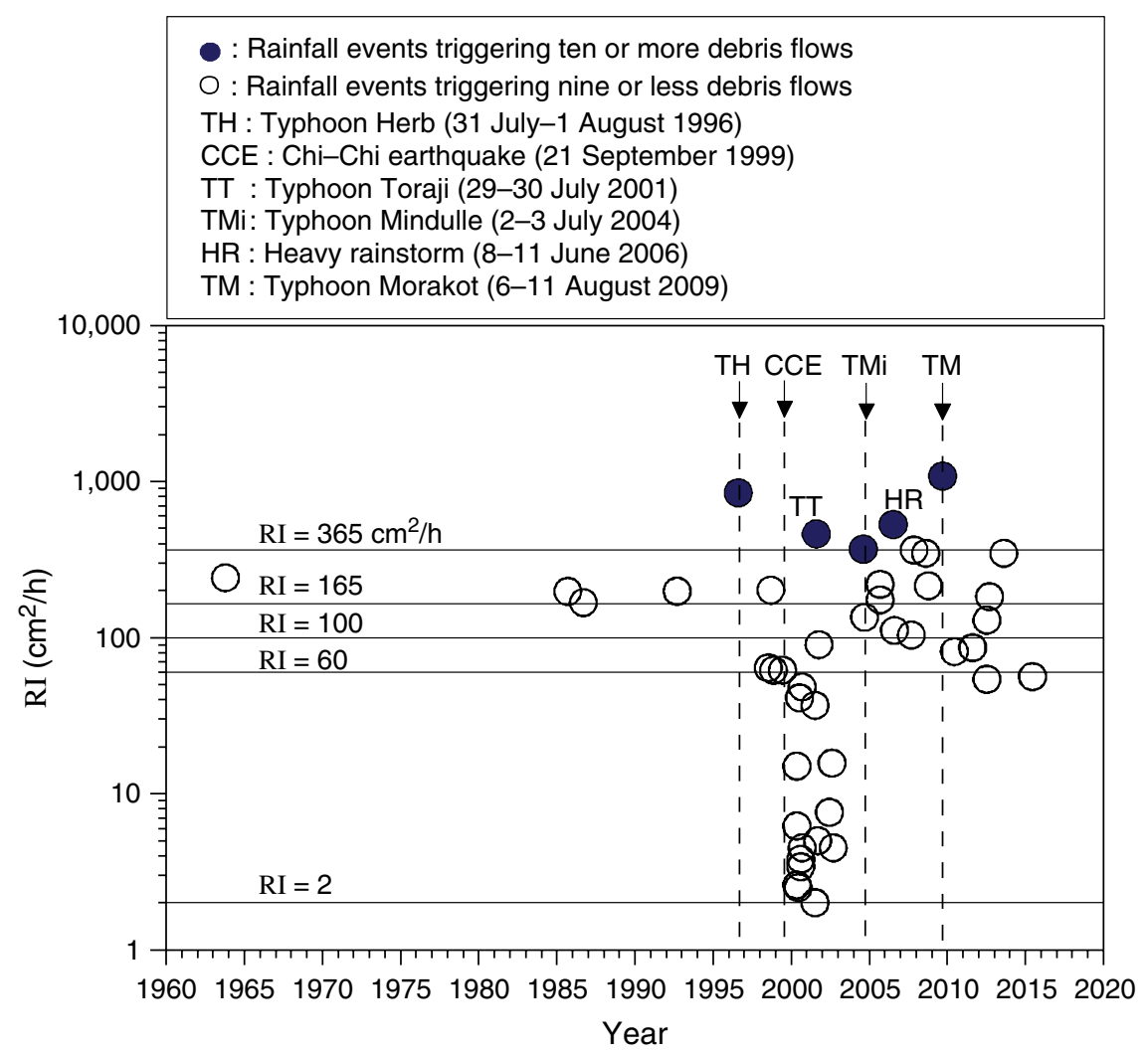

Figure 2: The variations in rainfall index (RI) for all rainfall events triggering debris flows between 1963 and 2009 in the Chenyulan watershed (Modified from [2]).

lowered the critical rainfall threshold for debris-flow occurrence in the subsequent five years. After the CCE, the critical RI dropped sharply to approximately $2 \mathrm{~cm}^{2} / \mathrm{h}$, which was 30 times lower than that before the CCE (critical RI $=60 \mathrm{~cm}^{2} / \mathrm{h}$ ). The results also showed that, approximately five years after the CCE, the critical RI gradually recovered from 2 to $100 \mathrm{~cm}^{2} / \mathrm{h}$ (i.e., the critical RI between TMi and TM).

\section{RELATIONSHIP BETWEEN THE PROBABILITY OF DEBRIS-FLOW OCCURRENCE AND RETURN PERIOD}

Return period $T$ is the average interval in years between events equalling or exceeding a certain magnitude. $T$ responds to the long-term hydrological characteristics of an area and is useful for hydrological or hydraulic design. Therefore, the RI associated with $T$ was determined, and the relationship between the probability of debris-flow occurrence and $T$ was developed.

\subsection{Return period of rainfall}

Many methods, such as the formulas by Weibull, Jenkinson and Gringorten; the computational methods as well as the modified Gumbel method, have been used to evaluate the return period $T$ of rainfall [12]. The Weibull formula was used to estimate $T$ for the rainfall of annual 
maximum series in this study because it can predict much shorter return periods of extreme events than the other methods [12]. T estimated by Weibull formula is

$$
T=(n+1) / m
$$

where $n$ refers to the number of years in the record and $\mathrm{m}$ is the rank of a value in a list ordered by descending magnitude. The RI data of the annual maximum series collected in the Chenyulan watershed between 1960 and 2013 were used to determine T. Figure 3 shows the empirical relationship between RI and $T$, which can be expressed as

$$
T=(\mathrm{RI} / 180)^{2.27}+0.98
$$

Equation (2) provides good estimates of RI with $T$ values of less than 50 years. Debris flows could be triggered at lower RI values, corresponding with lower $T$ values for rainfall events within five years after the CCE, as shown by the cross symbols in Fig. 3. Five extreme rainfall events are also shown in Fig. 3. The extreme events mostly had $T$ values exceeding eight years. The $T$ value for the critical RI affected by the CCE was approximately one year, much smaller than that affected by extreme events.

\subsection{Probability of debris-flow occurrence}

The $P$ of debris-flow occurrence for a rainfall event greater than a value of RI can be calculated by the number $\left(N_{\mathrm{D}}\right)$ of rainfall events that have triggered debris flows divided by the

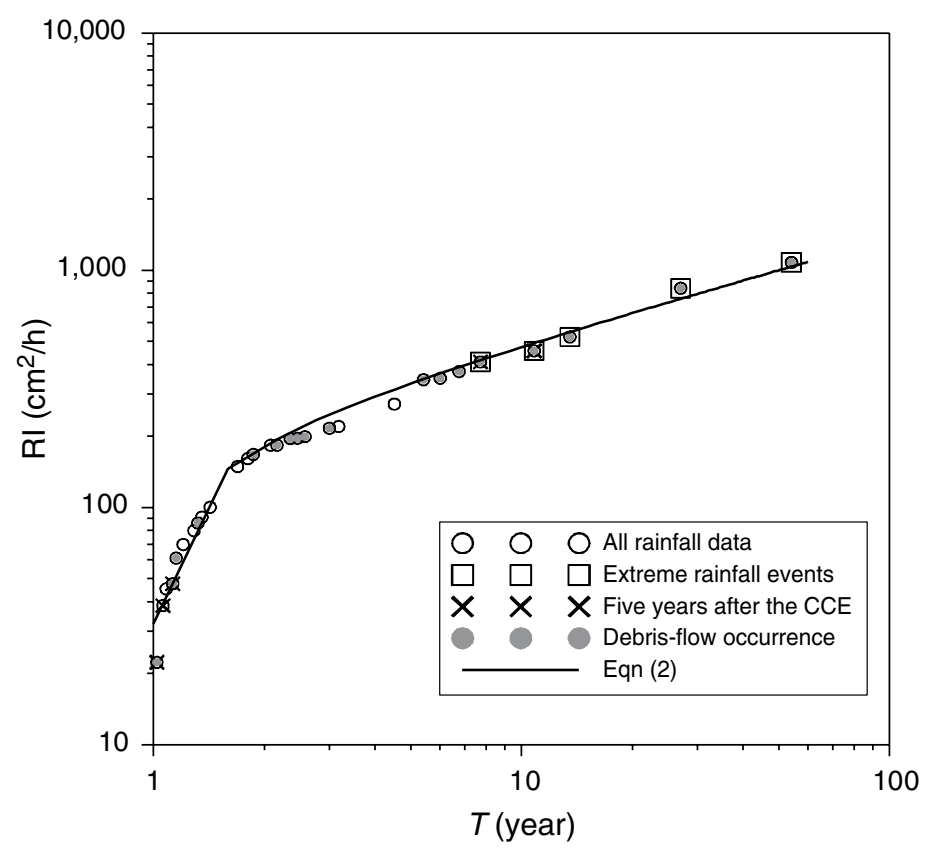

Figure 3: The relationship between the rainfall index (RI) and the return period $(T)$ in the Chenyulan watershed. 
number $\left(N_{\mathrm{R}}\right)$ of rainfall events, where $P=N_{\mathrm{D}} / N_{\mathrm{R}}$. Hence, the $P$ for a rainfall event with given RI or $T$ values corresponding to RI (based on the data in Fig. 3 ) could be determined. Three empirical curves of $P$ versus RI or $T$ based on different periods were developed. The three periods were: (i) the CCE-affected period (CCEAP), (ii) the extreme rainfall-affected period (ERAP) and (iii) the whole period (WP) between 1985 and 2013; the critical RI dropped sharply to approximately $2 \mathrm{~cm}^{2} / \mathrm{h}$, which was 30 times lower than that before the CCE (critical RI $\left.=60 \mathrm{~cm}^{2} / \mathrm{h}\right)($ Fig. 2). The CCE significantly lowered the critical rainfall threshold for debris-flow occurrence in the subsequent five years [2, 8]. Hence, the CCEAP was considered to be the period of five years after the CCE. Because the critical RI of debris-flow occurrence was affected by extreme rainfalls and the affected periods could reach three years [9], data within three years after extreme rainfalls were selected to develop the relationship of $P$ versus RI or $T$ for the ERAP. Finally, the WP considered the data of whole period (1985-2013), including CCEAP and ERAP.

Figure 4 shows the relationships between $P$ and $T$ for the three periods, which can be expressed in the form of a logistic function [12]

$$
P=\frac{1}{1+\mathrm{e}^{-(\alpha+\beta T)}}
$$

where $\alpha$ and $\beta$ are empirical coefficients that can be determined by fitting the given data. The empirical coefficients $\alpha$ and $\beta$ at for the four periods are listed in Table 2 .

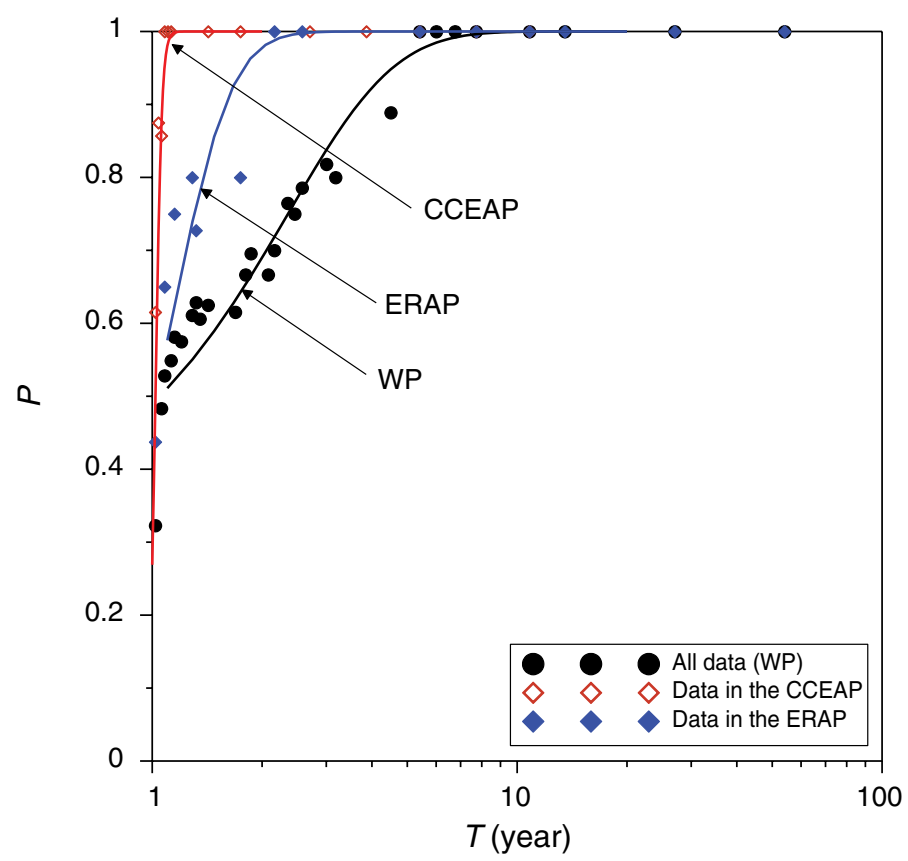

Figure 4: The $P-T$ relationship for the Chi-Chi earthquake-affected period (CCEAP), extreme rainfall-affected period (ERAP), and the whole period (WP) 
Table 2: Empirical coefficients of $\alpha$ and $\beta$ at in the three studied periods.

\begin{tabular}{lcc}
\hline Period & $\alpha$ & $\beta$ \\
\hline I. $\quad$ Whole period (WP) (1985-2013) & -1.11 & 0.98 \\
II. Chi-Chi earthquake-affected period (CCEAP) & -50.0 & 48.5 \\
III. Extreme rainfall-affected period (ERAP) & -3.97 & 3.89 \\
\hline
\end{tabular}

$P$ rose significantly after an extreme rainfall event or the CCE at the same $T$ or under the same rainfall condition. In particular, the $P$ value affected by CCE was markedly higher than that affected by extreme rainfalls. For example, $P=59 \%$ at $T=1.5$ years (see black curve in Fig. 4), while $P$ increases to $87 \%$ after an extreme rainfall event (see blue curve) and $P=$ $100 \%$ after the CCE (see red curve). The benefits of developing the $P-T$ relationship (Fig. 3 ) include that $P$ values can be evaluated at various $T$ values (or different rainfall conditions) to understand how $P$ is affected by the CCE or extreme rainfall.

\section{APPLICATION}

The relationship between $P$ and $T$ were applied to evaluate the probability of debris flow occurrence after recent extreme rainfall events of Typhoon Morokot (TM). The heavy rainfall brought by TM in August 2009 had a maximum hourly rainfall of $123 \mathrm{~mm}$ and 48-h rainfall of 2,361 mm (measured at Alishan rainfall station), which caused numerous debris flows that buried more than 20 houses in Shenmu, Tongfu and Xinyi villages [12] in the Chenyulan watershed.

The $P-T$ relationship of the WP is

$$
P=\frac{1}{1+e^{1.11-0.98 T}}
$$

and the $P-T$ relationship of the ERAP is

$$
P=\frac{1}{1+e^{3.97-3.89 T}}
$$

where $T$ is associated with RI and can be expressed by eqn (2). The probability of debris-flow occurrence can be determined when RI is given according to eqns (4) or (5).

However, the two equations were developed based on different periods and different data sets, and the valid conditions for the two equations may not be identical. Equation (4) predominantly reflects the long-term characteristics of debris-flow occurrence, and cannot reflect the short-term characteristic caused by extreme events. In contrast, eqn (5) focuses on the influence of extreme rainfall events. Hence, field data of debris-flow occurrence and rainfall were collected to assess the proposed equations.

Figure 5 shows the variation in the predicted $P$ (blue line) by eqn (4) and the three peaks labelled with "OCC" in the figure represent debris flow events. There were two debris flow events were reasonably predicted by eqn (4), that the predicted $P$ are exceeding $50 \%$. One debris flow event during Typhoon Talim was not predicted successfully in association with the events occurring within three years after the extreme rainfall event TM. The RI for debrisflow occurrence decreased in the early stage after the extreme rainfall event owing to the fact that extreme rainfalls result in large amounts of loose debris in gullies and on slopes. When 


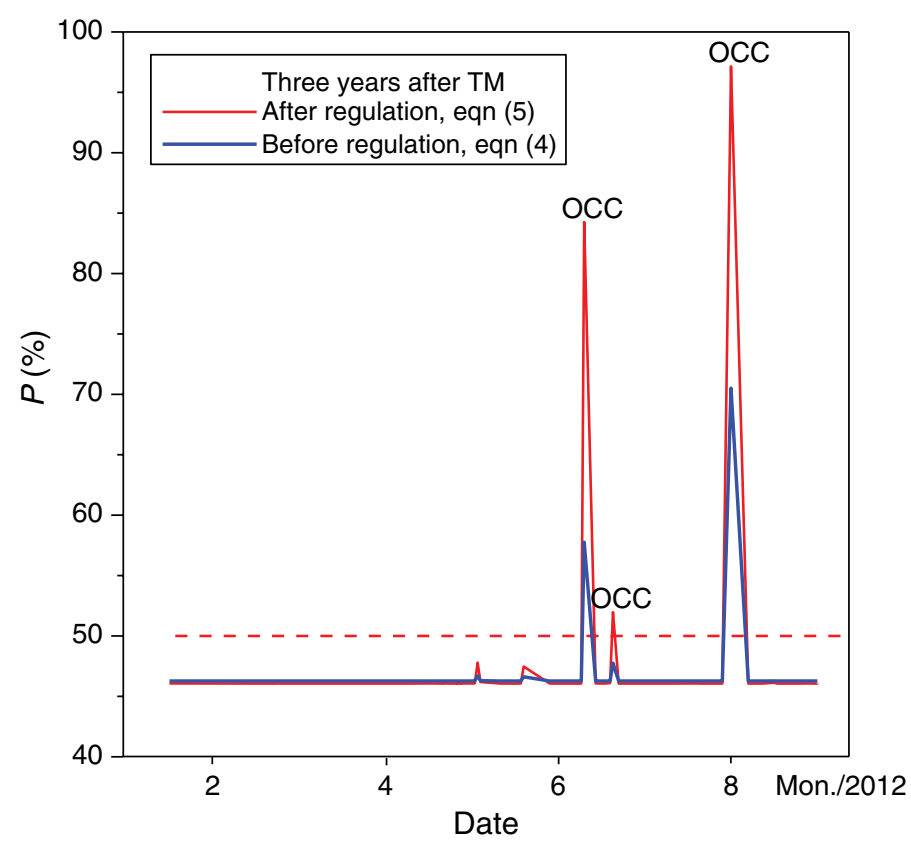

Figure 5: Probabilistic model of debris-flow occurrence in the whole period (WP, the blue line) compared with that in the extreme rainfall-affected period (ERAP, the red line).

the $P-T$ relationship in ERAP (eqn (5)) was used, instead of eqn (4), the predicted $P$ (red line) with $p>50 \%$ was in agreement with the field data of debris-flow occurrence.

\section{CONCLUSIONS}

The RI associated with return period $(T)$ was analysed in the Chenyulan watershed. The extreme events triggering numerous debris flows mostly had $T$ values exceeding eight years. The $T$ value for the critical RI affected by the CCE was approximately one year, much smaller than that affected by extreme events. The empirical relationships between the probability of debris-flow occurrence $P$ and $T$ based on the CCE and extreme rainfalls, i.e., the empirical models for the CCEAP and ERAP, were developed. $P$ increased significantly after extreme rainfall events or the CCE at the same $T$. In particular, the $P$ value influenced by the CCE was markedly higher than that affected by the extreme rainfall. $P=59 \%$ at $T=1.5$ years while $P$ increases to $87 \%$ after an extreme rainfall event and $P=100 \%$ after the CCE. The empirical relationship between $P$ and $T$ was applied to evaluate $P$ during recent rainfall events after the extreme rainfall of TM, which showed that the model was reasonable for explaining debrisflow occurrence. The benefits of developing the $P-T$ relationship include that $P$ values can be evaluated at various $T$ values (or different rainfall conditions) to understand how $P$ is affected by the CCE or extreme rainfall. The methods proposed in this study could be used by researchers interested in studying debris flows in other regions and the results could be used by policy-makers to create hazard mitigation plans and warnings. 


\section{ACKNOWLEDGEMENT}

This study received financial support from the Ministry of Science and Technology, Taiwan (MOST 105-2625-M-211-001).

\section{REFERENCES}

[1] Dong, J.J., Lee, C.T., Tung, Y.H., Liu, C.N., Lin, K.P. \& Lee, J.F., The role of the sediment budget in understanding debris flow susceptibility. Earth Surface Processes and Landforms, 34, pp. 1612-1624, 2009. DOI: 10.1007/978-94-015-8404-3_6.

[2] Chen, J.C., Huang, W.S., Jan, C.D. \& Yang, Y.H., Recent changes in the number of rainfall events related to debris flow occurrence in the Chenyulan Stream Watershed, Taiwan. Natural Hazards and Earth System Science, 12, pp. 1539-1549, 2012. DOI: 10.5194/nhess-12-1539-2012.

[3] Jakob, M., Bovis, M. \& Oden, M., The significance of channel recharge rates for estimating debris flow magnitude and frequency. Earth Surface Processes and Landforms, 30, pp. 755-766, 2005. DOI: 10.2113/gseegeosci.I.1.11.

[4] Lin, C.W., Shieh, C.L., Yuan, B.D., Shieh, Y.C., Liu, S.H. \& Lee, S.Y., Impact of ChiChi earthquake on the occurrence of landslides and debris flows: Example from the Chenyulan River watershed, Nantou, Taiwan. Engineering Geology, 71, pp. 49-61, 2003. DOI: 10.1016/S0013-7952(03)00125-X.

[5] Liu, C.N., Huang, H.F. \& Dong, J.J., Impacts of September 21, 1999 Chi-Chi earthquake on the characteristics of gully-type debris flows in central Taiwan. Nature Hazards, 47, pp. 349-368, 2008. DOI: 10.1007/s11069-008-9223-9.

[6] Chen, J.C., Variability of impact of earthquake on debris flow triggering conditions: Case study of Chen-Yu-Lan Watershed, Taiwan. Environmental Earth Sciences, 64(7), pp. 1787-1794, 2011. DOI: 10.1130/REG7-p93.

[7] Zhang, A.B. \& Zhang, L.M., Impact of the 2008 Wenchuan earthquake in China on subsequent long-term debris flow activities in the epicentral area. Geomorphology, 276, pp. 86-103, 2017. DOI: 10.1016/j.geomorph.2016.10.009.

[8] Chen, J.C., Jan, C.D. \& Huang, W.S., Characteristics of rainfall triggering of debris flows in the Chenyulan Watershed, Taiwan. Natural Hazards and Earth System Science, 13, pp. 1015-1023, 2013. DOI: 10.5194/nhess-13-1015-2013.

[9] Shin, T.C. \& Teng, T.L., An overview of the 1999 Chi-Chi, Taiwan earthquake. Bulletin of the Seismological Society of America, 91, pp. 895-913, 2001. DOI: $10.1785 / 0120000738$.

[10] Chen, J.C., Study on the criteria of debris flow occurrence after extreme rainfalls. Report of Minister of Science and Technology, Taiwan (No. MOST 104-2625-M-211001), 2016 (in Chinese).

[11] Chen, J.C., Huang, W.S., Jan, C.D. \& Tsai, Y.F., Rainfall conditions for the initiation of debris flows during Typhoon Morakot in the Chen-Yu-Lan watershed in central Taiwan. Proceedings of the 5th International Conference on Debris flow Hazards Mitigation, Padua, Italy, eds. R. Genevois, D.L. Hamilton \& A. Prestininzi, pp. 31-36, 2011.

[12] Makkonen, L., Plotting positions in extreme value analysis, Journal of Applied Meteorology and Climatology, 45, pp. 334-340, 2006. DOI: 10.1175/JAM2349.1.

[13] Hosmer, D.W. \& Lemeshow, S., Applied Logistic Regression, 2nd ed., Wiley Series in Probability and Statistics, New York, 2000. 